\title{
El significado del procedimiento administrativo **
}

\section{The meaning of the administrative procedure}

SUMARIO

Introducción. 1. Una noción formal del procedimiento administrativo. 2. La comprensión sustantiva del procedimiento administrativo. 3. Una comprensión funcional del procedimiento administrativo chileno. Conclusiones. Referencias.

\section{RESUMEN}

El artículo busca presentar una noción sustantiva del 'procedimiento administrativo', esto es, una comprensión que prescinda del significado meramente procedimental o formal que se ha consolidado en Chile a partir de la definición adoptada por la Ley de Bases de Procedimiento Administrativo ("LBPA") y que se haga cargo de las finalidades institucionales que se han asignado al procedimiento administrativo por la doctrina comparada. El trabajo desarrolla una explicación acerca de los orígenes de la comprensión formal y expone la doctrina que se ha consolidado en Europa para explicar la institución desde un punto de vista sustancial. Se sostiene que dicha noción sustantiva puede ser construida también en Chile a partir de una lectura sistemática de algunas de las disposiciones de la ley sobre procedimientos administrativos.

* Doctor en Derecho Público por la Universidad de Roma 'Tor Vergata'. Profesor asociado de derecho administrativo en la Pontificia Universidad Católica de Valparaíso (Valparaíso, Chile). Correspondencia: martin.loo@pucv.cl Agradezco las valiosas observaciones que hizo Matías Lepe a un borrador del artículo. Agradezco, asimismo, las sugerencias y críticas realizadas por los pares evaluadores en el proceso de revisión de este trabajo.

${ }^{* *}$ Recibido el 17 de octubre de 2016, aprobado el 1. . de marzo de 2017.

Para citar el artículo: Loo GutiéRrez, M. El significado del procedimiento administrativo. Derecho del Estado n. ${ }^{\circ} 38$, Universidad Externado de Colombia, enero-junio de 2017, pp. 155 175. Dor: https://doi.org/10.18601/01229893.n38.06 
PALABRAS CLAVE

Procedimiento administrativo, administración pública, acto administrativo, Chile, control administrativo, Ley chilena de Bases del Procedimiento Administrativo de 2003, Ley 19880.

\section{ABSTRACT}

The article seeks to present a substantive notion of the 'administrative procedure', that is, an understanding that departs from the merely procedural or formal meaning that has been consolidated in Chile from the definition adopted by the Administrative Procedures Act ("LBPA") and analyses the institutional purposes that have been assigned to the administrative procedure by foreign literature. The paper develops an explanation about the origins of this formal understanding and exposes the doctrine that has been consolidated in Europe to explain the institution from a substantial point of view. It is argued that this substantive notion can also be constructed in Chile from a systematic reading of some of the provisions of the law on administrative procedures.

\section{KEYWORDS}

Administrative procedure, public administration, Chile, administrative act, administrative control, chilean Administrative Procedure Act 2003, Act 19880.

\section{INTRODUCCIÓN}

La Ley 19880, de Bases del Procedimiento Administrativo (“LBPA”), significó un avance gigantesco en el desarrollo del derecho administrativo chileno. Su dictación marcó un antes y un después en el crecimiento dogmático y jurisprudencial de un área del derecho que había sido, por décadas, literalmente olvidada por el legislador ${ }^{1}$. Sus pocos cultores habían debido contentarse con

1 La relevancia de la LBPA en el crecimiento dogmático del derecho administrativo chileno ha sido claramente expuesta por la doctrina. De esta suerte, por ejemplo, Luis Cordero Vega, al destacar la enorme influencia que Pedro Pierry tuvo en la consolidación de la jurisprudencia de la Corte Suprema, recuerda que este, a diferencia de Urbano Marín, otro juez cuyos fallos marcaron el desarrollo de nuestro derecho administrativo, contó con una "herramienta que Marín no tuvo desde el inicio de su gestión: la ley de procedimiento administrativo y sus principios". Véase Cordero VeGA, 2016. En definitiva, la consolidación de lo que el autor denomina "Factor Pierry" en la jurisprudencia de la Corte de casación chilena fue posible, entre otros motivos, porque Pierry pudo echar mano a un instrumento normativo clave al momento de enjuiciar la legalidad de la actuación formal de la Administración, esto es, la LBPA. Por lo demás, la doctrina comparada reconoce en la regulación del procedimiento administrativo un signo de madurez del respectivo ordenamiento. Así, BARNES $(2011,85)$ afirma que "la evolución y madurez del Derecho administrativo corre paralela, en muchos casos, a la emergencia del procedimiento administrativo como institución". 
muchas normas fragmentarias y asistemáticas y con solo un par de normas generales, como la Ley de Municipalidades, de 1976, o la Ley Orgánica Constitucional de Bases Generales de la Administración del Estado, de 1986.

Con todo, en el primer lustro del nuevo siglo esta situación mostró un cambio significativo gracias a la dictación de dos leyes que -como el paso del tiempo se encargaría de demostrar-fueron fundamentales para la consolidación del derecho administrativo chileno: la ya mencionada Ley de Bases de Procedimiento Administrativo y la Ley de Contratos de Suministro y de Prestación de Servicios (Ley 19886). Su adopción inauguró una época en que el legislador chileno manifestó creciente interés en el establecimiento de normas generales y sistemáticas para nuevos sectores regulativos. El paradigma de esta mejor y más detallada regulación lo encontramos en el derecho ambiental, área que incluso puede vanagloriarse de un 'lujo' que el derecho administrativo general $-\mathrm{y}$, por tanto, los ciudadanos comunes y corrientes- no tiene, esto es, unos tribunales contencioso administrativos propios. Sabemos, sin embargo, que la existencia y correcta operatividad de este subsistema normativo e institucional (el 'derecho administrativo ambiental') no habría sido posible si antes no se hubiera reflexionado sobre los grandes tête de chapitre del derecho administrativo general. Ello lo debemos a los valerosos profesores que trabajaron en medio de un árido desierto normativo y con una jurisprudencia no siempre sensible a las particularidades de la disciplina. Pero, como se dijo, en los primeros cinco años del nuevo siglo ese desierto normativo comenzó a florecer gracias a esporádicas pero significativas intervenciones legislativas de entre las cuales cabe destacar, precisamente, la LBPA.

Pese a la gran atención doctrinaria y jurisprudencial que bien ha merecido esta ley, debe reconocerse que ella surgió en un ambiente cultural poco preparado para el análisis dogmático, profundo y reflexivo, de sus disposiciones ${ }^{2}$. A este respecto es interesante recordar que, hacia fines de los años cincuenta, Alejandro Nieto refería que una de las razones de la atávica oposición de la doctrina alemana a la dictación de una ley general de procedimiento administrativo se encontraba en la "peligrosidad que supone la creación de un derecho nuevo sin la debida fundamentación científica y jurisprudencial previa" 3 . En Chile no se presentó una inquietud similar: recibimos la ley y, con pueril entusiasmo, nos dispusimos a estudiarla y a usarla, esperando que

2 Autorizados autores estarían en desacuerdo con este juicio. En efecto, parte de la doctrina chilena sostiene que la cultura jurídica del país se encontraba preparada para recibir esta ley, gracias a la labor desarrollada por la Contraloría General de la República la cual, con su jurisprudencia, había logrado consolidar un sistema de principios sobre el procedimiento administrativo a partir del análisis del 'derecho general de petición ante la autoridad'. El autor califica la jurisprudencia de dicho órgano de control como "pilar estructurante" de la procedimentalización administrativa. En este sentido puede consultarse JARA SCHNETTLER (2013, 64-65).

3 NiETO $(1960,108)$. 
la experiencia y la reflexión de nuestra -reducida- comunidad académica sirviera para ponernos a recaudo de los efectos que podría tener la introducción de una nueva legislación sin el desarrollo previo de un adecuado sustento dogmático.

En buenas cuentas, se trató de hacer operativa una ley sin una reflexión substantiva y extensa que la antecediera. Así, Luis Cordero, en una temprana monografía sobre la LBPA, manifestó sus preocupaciones al respecto del siguiente modo: "Esta ley ha sido publicada sin que exista claridad sobre cuántos tipos de procedimientos administrativos existen en nuestro sistema, la naturaleza formal o informal de los mismos [y con una] ausencia de capacitación en la forma y en el fondo de la aplicación de esta ley"4. Las consecuencias de esto se aprecian hasta el día de hoy en nuestra comprensión acerca de qué es el procedimiento administrativo, cuestión que impacta necesariamente sobre el para qué se lo ha regulado.

El presente artículo pretende hacerse cargo de ambos problemas. Para ello se expondrá qué ha sostenido la doctrina al elaborar nociones formales acerca del procedimiento (1), luego se revisará cómo se ha sustantivado dicha noción, tanto en la doctrina chilena como comparada (2); a continuación se ofrecerá, utilizando la realidad legislativa chilena, una comprensión funcional del procedimiento administrativo que pueda servir para orientar una reflexión sobre los fines de sus reglas y principios (3), y se culminará exponiendo algunas conclusiones.

\section{UNA NOCIÓN FORMAL DEL PROCEDIMIENTO ADMINISTRATIVO}

El artículo 18, inciso $1 .^{\circ}$, LBPA define el procedimiento administrativo en los siguientes términos: "El procedimiento administrativo es una sucesión de actos trámite vinculados entre sí, emanados de la Administración y, en su caso, de particulares interesados, que tiene por finalidad producir un acto administrativo terminal".

De la definición transcrita resulta posible afirmar que la legislación chilena consagra, en modo expreso y claro, una noción 'formal' del procedimiento administrativo. Se trata de una definición que atiende al aspecto exterior del procedimiento, es decir, a la circunstancia de ser la sede en la cual se encadenan tanto actos administrativos no decisorios (los 'actos trámite') como actuaciones de los particulares. Unos y otros se encuentran orientados o, según la ley, tienen 'por finalidad' la producción de un 'acto administrativo terminal' (art. 18, inc. 1. ${ }^{\circ}$, LBPA), esto es, de una decisión formal emitida por un órgano de la Administración del Estado (art. $3^{\circ}$, inc. 2. ${ }^{\circ}$, LBPA). En este artículo llamaremos al tipo de noción que esta definición representa 'noción procedimental'. 
Esta 'noción procedimental' ha calado hondo en la doctrina administrativa.

De esta suerte, por ejemplo, Bocksang -siguiendo a Soto Kloss- expresa que el procedimiento ha podido "ser definido sucintamente como una sucesión de actos trámites destinados a la dictación de un acto terminal, siendo el acto administrativo terminal tanto el fin como la finalidad del procedimiento"s. Continúa señalando que, a pesar de su exactitud, esta definición queda "completamente vacía dentro de su formalidad", pero solo porque deja de hacer alusión a la finalidad del acto administrativo. La finalidad de esta actuación estatal sería, según el autor, la racionalidad de la conducta de la Administración. Por tanto, el procedimiento administrativo, de acuerdo con Bocksang, "viene a convertirse en una institución jurídica cuyas carnes y nervios propios se derivan de sus ínsitos atributos [...] y cuya concreción debiese entronizar a la racionalidad como el fundamento primero del obrar de la Administración"'.

Por su lado, en un temprano artículo publicado en las páginas de la revista del Consejo de Defensa del Estado, Rojas señalaba que "el procedimiento no supone más que una sucesión ordenada de actuaciones", agregando que "desde la perspectiva de los elementos del acto administrativo, el procedimiento constituye una forma externa necesaria" 7 .

Por su parte, Cordero Vega, a pocos meses de la entrada en vigencia de la ley, concibió al procedimiento administrativo como la "relación ordenada de una serie de actuaciones, de la Administración o los interesados, que al estar relacionadas directamente sirven para la producción de una decisión administrativa terminal". Nuevamente se logra identificar el tópico central de este tipo de nociones, esto es, que el procedimiento tiende todo al respeto de formas destinadas a emanar un acto administrativo terminal. De este modo, "el procedimiento administrativo siempre se instruye para que produzca efecto, es decir, una decisión final"».

La comprensión formal del procedimiento administrativo que se viene exponiendo no solo se advierte en el derecho chileno, sino que también en la obra de distintos autores extranjeros.

De este modo, en España, por ejemplo, se ha sostenido que el procedimiento es el "conjunto de actuaciones efectuadas en orden legalmente predeterminado bajo la forma de actos preparatorios o de trámite y reflejadas documentalmen-

5 Bocksang Hola (2006, 3) (cursivas originales).

6 Bocksang Hola $(2006,3-6)$.

7 Rojas VARAs $(2004,22$; cursivas nuestras).

8 CoRdero VEGA $(2003,46-47)$. Debe señalarse desde ya que, en una obra más reciente, Cordero denuncia el formalismo que se advierte en la comprensión explicitada tanto por la LBPA como por la doctrina más tradicional -de la que, en definitiva, se separa- en el sentido de que ambas ven "el procedimiento administrativo en su perspectiva adjetiva meramente defensiva, con olvido de sus potencialidades". Véase Cordero VeGA $(2015,321)$. Volveremos sobre esto en el punto 3 de este artículo. 
te en los correspondientes expedientes administrativos; actuaciones que se dirigen a preparar y prefigurar la declaración final resolutoria con relevancia jurídica bajo la forma de actos definitivos o resoluciones"9.

Esta comprensión cuenta con una larga tradición en el derecho español. En efecto, poco tiempo después de la publicación de la ley de procedimiento administrativo de 1958, la doctrina española aseveró que el procedimiento es la "serie de trámites y de formalidades a que deben someterse los actos de la administración" 10 , comprensión imperante en la época, como se desprende de las palabras de la exposición de motivos de la referida ley, según la cual "el procedimiento administrativo es el cauce formal de la serie de actos en que se concreta la actuación administrativa para la realización de un fin" En fin, más recientemente, Barnes ha dicho que este tipo de nociones ven a la institución en "una imagen lineal, como conjunto de actos de autoridad encadenados con el objeto de dictar una resolución final dotada de autoridad" 12 .

Este concepto se trasladó exitosamente a Suramérica, como dan cuenta las palabras de Brewer-Carías, quien sostiene que "el procedimiento administrativo [...] se configura como un conjunto de actos y actuaciones estrechamente vinculados entre sí, con el objeto de obtener un resultado concreto que, generalmente, se materializa en un acto administrativo"13.

Como puede verse, la comprensión formal del procedimiento se encuentra bastante consolidada en la literatura en lengua española, al punto que el ya citado artículo 18 LBPA la ha establecido como noción oficial en la legislación chilena. Por ello, conviene preguntarse cómo es posible que haya calado tan hondo dicho modo de entender esta institución fundamental y, sobre todo, cuál es el origen de esta noción 'meramente procedimental'.

Al respecto, pienso que la raíz de esta noción formal puede encontrarse en los orígenes mismos del procedimiento administrativo moderno, esto es, en las ideas desarrolladas en el seno de la Escuela de Viena por Adolf Merkl ${ }^{14}$.

9 Parejo Alfonso $(2012,317)$

10 López-Nieto y Mallo $(1960,20)$

11 Apartado v, punto 1, de la Exposición de motivos de la Ley del Procedimiento Administrativo, del 17 de julio de 1958 (España).

12 BARNES $(2011,82)$.

13 BREWER-CARÍAS $(1990,147)$.

14 La doctrina italiana, sin embargo, antedata el nacimiento del procedimiento administrativo a la ley que instituyó el Tribunal Administrativo Supremo austriaco en 1875. Dicha ley atribuyó competencia a este tribunal para pronunciarse sobre la anulación de las decisiones administrativas que fueran adoptadas con infracción de las formas esenciales del procedimiento; aunque no determinaba cuáles eran dichas formas. En este sentido, véase TEDESCHINI (1986, 872): "Secondo alcuni autori, la nascita dell' istituto è databile con precisione al 1875, anno in cui venne costituito a Vienna il Supremo Tribunale amministrativo (Verwaltungsgerichtshof) $e$, nella legge che ne disciplinava l'organizzazione e le competenze, gli veniva attribuito fra l'altro il compito di annullare quelle decisioni o provvedimenti che fossero stati emanati trascurando le forme essenziali della procedura amministrativa". Sin embargo, mi juicio encuentra sostén 
Para Merkl "todas las funciones estatales y, en particular, todos los actos administrativos, son metas que no se pueden alcanzar sino por determinados caminos", ya que, "en el fondo, toda administración es procedimiento administrativo y los actos administrativos se nos presentan como meros productos del procedimiento administrativo" "15; de modo que resulta claro que, para el autor, el procedimiento administrativo no es sino el 'camino' que la Administración Pública debe recorrer para emanar un acto administrativo el cual, por su parte, no es más que el 'mero producto' de dicho 'camino'. La pregunta que surge inmediatamente es: ¿por qué razón se concibió de este modo al procedimiento?

La respuesta, pienso, es que esta comprensión formal del procedimiento administrativo encuentra su origen en el ambiente cultural del cual Merkl mismo fue un protagonista de primer orden. Me refiero a las reflexiones desarrolladas por la Escuela de Viena y, especialmente, a la concepción jerárquica del ordenamiento (Stufenbau der Rechtsordnung) ${ }^{16}$, contribución clave del mismo Merkl a la teoría del derecho nacida de dicha Escuela ${ }^{17}$. Como se sabe, de acuerdo con dicha comprensión jerárquica del ordenamiento, la producción de actos de aplicación-creación del derecho no es sino un proceso de deducción de consecuencias jurídicas ya implícitas en normas de superior rango o jerarquía.

Esta comprensión se encontró a la base de la Teoría pura del derecho. En efecto, como da cuenta el mismo Kelsen, la relación entre una norma de superior nivel y una de menor rango se encuentra predeterminada o vinculada. Es decir, en la regulación de la norma de menor rango (como una decisión judicial o administrativa), la norma de superior nivel no solo condiciona

en la opinión de GarCía de EnTERRía y FernáNDEZ (2008, 452-453), quienes aseveran que "la aportación de Merkl, al margen de cualesquiera otras consideraciones, debe estimarse decisiva".

15 MERKL (2004, 272; cursiva nuestra).

16 Ver SORDI $(1987,189)$, donde explícitamente se vincula la idea de procedimiento con el modelo teórico creado por la Escuela de Viena: "L'ampia generalizzazione del concetto di Prozess e di Verfahren che si celebra nelle pagine di Adolf Merkl - 'denn der Prozess ist seinem Wessen nach im Bereich aller Staatsfunktionen möglich'- sembra a prima vista strettamente ed unicamente dipendente da quel modello teorico offerto dalla costruzione a gradi dell'ordinamento".

17 La literatura atribuye a Merkl la elaboración del nombre con el cual pasaría a ser conocida una de las ideas centrales de la teoría pura. Así, STolleis $(2004,154)$, refiriéndose a la obra de Kelsen afirma que "The result was his 1920 work Das Problem der Souveränität und die Theorie des Völkerrechts ('The problem of sovereignty and the theory of international law'), which developed the basic idea of 1911 into a more dynamic perspective that trascended the individual state and into a self-contained system of legal theory. Adolf Merkl (1890-1970) supplied the slogan of the 'hierarchical ordering of norms' (Stufenbau der Rechtsordnung)"; PAUlson (2013, p. 22), luego de una cita a la obra de Kelsen, afirma: "Kelsen is clearly hinting at the Stufenbaulehre or doctrine of hierarchical structure that he took [...] from his gifted and much neglected colleague, Adolf Julius Merkl"; y CARRINO (2016, 116), quien afirma que "Merkl never did give us any specific philosophy of law. Yet his contribution to the reine Rechtslehre did prove to be decisive, since the conception of law as a system-and in particular as a hierarchically organized system (the so-called Stufenbau)-traces back to him". 
el contenido, sino también el proceso a través del cual la norma inferior es creada $^{18}$.

Esta idea general, aplicable a los procesos legislativo, judicial y, por cierto, administrativo, se encuentra bien expresada por Merkl. En sus palabras, "en un sentido más riguroso y técnico se habla de procedimiento jurídico solamente cuando el camino que conduce a un acto estatal no se halla a la libre elección del órgano competente para el acto, sino que está previsto jurídicamente, cuando, por tanto, el camino que se recorre para llegar al acto constituye aplicación de una norma jurídica" ${ }^{19}$.

Este razonamiento se insertó dentro del proceso general de 'jurisdiccionalización' del poder público vivido en Austria en la década de 1920. Dicho proceso afectó, en primer lugar, al legislador democrático con la creación de la Corte Constitucional austriaca (arts. 137 ss. de la Constitución Federal Austriaca de 1920) y consistió fundamentalmente en la extensión de las formas procesales y, en particular, de la fuerza de la sentencia judicial a territorios resistentes a la difusión de lo 'jurídico'. Dicha jurisdiccionalización fue percibida como garantía de la legalidad del proceso de ejecución de la Constitución y la ley ${ }^{20}$.

Es así que el procedimiento se transformó en el 'camino' (Weg) a través del cual se mueve el proceso de ‘creación-aplicación' del derecho, de modo que, en palabras de la doctrina italiana, el procedimiento no es otra cosa que los escalones del camino que corre a lo largo de la 'pirámide' del ordenamiento ${ }^{21}$.

Como se ve, se trata de una comprensión que atiende a la forma de producción de los actos del poder estatal y que radica en dichas formas una garantía de juridicidad en el ejercicio del poder. Así, "el procedimiento se

18 Kelsen (2011, 101-102), donde se explicita que "La relación entre el nivel superior y el inferior en un ordenamiento jurídico, como la que existe entre la constitución y la ley o entre esta y la sentencia judicial, es una relación de determinación o vinculación; como ya se ha expuesto, la norma de nivel superior regula el acto por el cual se crea la norma de nivel inferior (o bien, si es el caso, el acto de ejecución) y establece no solo el procedimiento sino también, eventualmente, el contenido de la misma".

19 Merkl $(2004,272)$. Véase también Barnes (2011, 81-82), quien luego de afirmar que la idea de secuenciar el proceso decisorio es tan antigua como el derecho mismo, expresa que "las decisiones judiciales -sentencias, autos, providencias-se adoptarían a través de un proceso. Las decisiones parlamentarias -desde la entrada del proyecto o de la proposición en la cámara hasta su aprobación y promulgación- seguirían su propio cauce: procedimientos legislativos. Finalmente, el ejecutivo y la administración sujetarían sus decisiones a un procedimiento administrativo".

20 Ver SORDI $(1987,187)$, donde se indica que "la giustizia costituzionale rappresentava una notevole estensione delle forme processuali e della sentenza a territori impervi e resistenti alla diffusione del giuridico, a controversie in cui la legge da parametro diveniva invece oggetto del giudizio".

21 En este sentido, Sord (1987, 189-190), quien señala que "processo [...] non è altro che la strada ('Weg') attraverso la quale scorre il complesso dossaggio tra 'creazione' ed 'applicazione' del diritto" De este modo "il procedimento amministrativo (...) diventa una 'Stufe' di quei 'Prozesswege' che corrono lungo la piramide dell'ordinamento". 
introduce en el interior del poder mismo, se convierte en forma de la decisión administrativa, el modo de hacerse del acto" administrativo ${ }^{22}$.

La razón de ello, según Merkl, se encuentra en la imposibilidad práctica de que la norma que haya de ejecutarse prevea todos los extremos y posibilidades de su aplicación. De esta forma, "un acto relativamente abstracto, que sirve como regla de producción de un acto relativamente concreto, no puede determinar a este último de manera completa, sino que proporciona, únicamente, una componente para su proceso de concreción y debe dejar sitio para otro componente: el arbitrio del órgano" 23 .

Por tal motivo, según Carrino, la aplicación del derecho resulta ser un acto de voluntad de quien lo aplica que no puede ser completamente determinado por el ordenamiento ya que, de un lado, tenemos las reglas legales existentes y, de otro, los actos (comparativamente más) subjetivos por medio de los cuales tales reglas son aplicadas ${ }^{24}$.

De este modo, aparece con claridad que la noción formal del procedimiento, de raigambre merkeliana, encuentra una explicación plenamente coherente dentro del aparato metodológico desarrollado por la Escuela de Viena. Ello porque, si cada acto de aplicación del derecho no es más que la concreción de una norma superior, la cual, junto con determinar parte del contenido de la decisión, establece también el camino (Weg) que debe seguirse para obtener su concreción, el acto administrativo no puede sino ser el resultado de una actividad de actualización de la norma, esto es, de un proceso 'binario' de aplicación-creación del derecho: de aplicación de una regla superior que lleva a la creación de una nueva regla, de grado inferior. Como puede verse, el formalismo procedimental encaja perfectamente en esta comprensión del ordenamiento jurídico.

Pero, contemporáneamente, es este formalismo el que explica y da pie para entender que la voluntad de quien decide (en nuestro caso, la Administración) no queda completamente marginada o excluida de la elaboración de la decisión. Ya lo hemos dicho: para Merkl, la norma de procedimiento (o, como él la denomina, el 'derecho procesal administrativo' ${ }^{25}$ ) determina el camino para adoptar una decisión y una parte del contenido de la misma,

22 Sordi $(1987,191)$. En idéntico sentido, BARNES 2011, p. 84, expresa que "el procedimiento administrativo [...] constituye ante todo un instrumento o mecanismo para la correcta aplicación de Derecho en manos de la administración imperativa, especialmente diseñado para el dictado de acto administrativos singulares (decisiones unilaterales), potencialmente de gravamen o restrictivos de derechos".

23 MerKL $(2004,182)$.

24 Véase CARRINO (2016, 117): "There is a legal system that exists as an objective entity, but there is also a subjectivity through which norms are created. Which is to say that the legal system is contemporaneously made up of autonomous determinants and heteronomous ones: On the one hand are the existing rules of law; on the other, the (comparatively) subjective acts through which those rules are applied".

25 MerKL $(2004,272)$. 
mas la norma no puede agotar exhaustivamente cada una de las posibilidades que la voluntad de quien decide puede imprimir en tal determinación. Merkl denomina dicho ámbito o espacio no colmado por la norma como 'arbitrio'; nosotros lo conocemos como 'discrecionalidad'.

$\mathrm{Y}$ es en este punto que logra percibirse cómo esta noción formal del procedimiento que toma pie en la doctrina austríaca, enormemente influenciada por la obra de Kelsen y Merkl, encuentra una racionalidad enteramente sustantiva y estrechamente vinculada a la demanda de democraticidad de la acción administrativa. Al suponerse que la producción de cada decisión administrativa está determinada, formal y sustancialmente, por una norma de superior rango (la ley) se adquiere un instrumento fundamental para el control de la legalidad de la actuación administrativa. De esta manera, con este instrumento, la formación de la voluntad administrativa viene entregada al ámbito jurídico, se transforma en un proceso abierto a la contradicción y al conocimiento de los distintos intereses en conflicto y que permite la participación del interesado en la formación de la decisión administrativa ${ }^{26}$. De esta manera, el procedimiento administrativo se transforma en un método para la correcta aplicación de derecho, para su aplicación imparcial, previsible y sin discriminaciones ${ }^{27}$.

Este punto es un logro relevante ya que consigue incluir a la decisión administrativa dentro del complejo 'procesal' que es la actuación del poder público contemporáneo, y ello porque "el 'proceso' es función del derecho en todos sus campos y planos" 28 .

Para concluir con esta parte, es necesario recordar que el trabajo de Merkl fue todo menos que infructuoso, toda vez que influyó decisivamente en la elaboración de la ley general procedimiento administrativo austríaca de $1925^{[29]}$. Siguiendo a Mannori y Sordi, se debe destacar la circunstancia de que esta ley surgiera, precisamente, en el primer ordenamiento continental que se representó la necesidad de establecer una justicia constitucional destinada a verificar la regularidad de la 'ejecución' de las disposiciones constitucionales por parte del legislador convirtiéndose, con ello, en el primer sistema institucional capaz de erigir a la jurisdicción como baluarte de la regularidad de dicha 'legis executio's0.

Creo que resulta inmediatamente claro cómo fue posible que, en un contexto cultural de este tipo, se advirtiera la necesidad de someter a un 'proceso' la formación de la voluntad administrativa; proceso que no tiene otro objeto

26 MANNORI y SORDI $(2006,464)$.

27 BARNes $(2011,82)$.

28 Merkl $(2004,274)$.

29 La Allgemeines Verwaltungsverfahrensgesetz, "AVG", de 21 de julio de 1925.

30 MANNORI y SORdi $(2006,465)$. 
que permitir a la jurisdicción controlar la juridicidad o regularidad de la 'ejecución' de la ley.

Puede verse, entonces, que la idea misma del procedimiento administrativo nace de una visión eminentemente formal sobre su función y naturaleza. Sin embargo, el formalismo que impregna este entendimiento no es sino fruto de la idiosincracia también formal de la teoría jurídica que le sirve de sustento, esto es, la teoría de la formación del ordenamiento jurídico por grados (la ya recordada Stufenbauhlehre). Pero, aquello que resulta paradójico es que, del intrínseco formalismo de la teoría que le da vida, surgen las instituciones que ayudan a la dogmática contemporánea a otorgar un sentido sustantivo al derecho administrativo y constitucional: a este, de la mano de la justicia constitucional; a aquel, con un procedimiento administrativo completamente volcado a la protección de los intereses generales y de los administrados y, por ello, enteramente sustantivado en sus finalidades.

No obstante, dichas finalidades de contenido sustantivo solo pueden alcanzarse con la elaboración de comprensiones más sofisticadas acerca de qué es el procedimiento administrativo. Repasaremos las principales manifestaciones de dicha tendencia en el apartado sucesivo.

\section{LA COMPRENSIÓN SUSTANTIVA DEL PROCEDIMIENTO ADMINISTRATIVO}

Corresponde en este apartado hacerse cargo de algunas comprensiones sustantivas sobre el procedimiento administrativo. Ellas surgen de la mano de la doctrina europea post-bélica y conciben el procedimiento como una instancia de adquisición de las informaciones relevantes para la adopción de decisiones administrativas materialmente justas, esto es, acordes con el interés de la comunidad a la cual la Administración debe servir.

En otras palabras, el formalismo de la que hemos llamado noción "procedimental' del procedimiento administrativo se morigera a través de la búsqueda de un significado que ponga en un plano superior no solamente la necesidad de garantías jurídicas a favor del ciudadano sino, también, la adecuada recolección de información por parte del órgano administrativo que le permita adoptar determinaciones ajustadas al interés general. Como sostienen García de Enterría y Fernández, "el procedimiento administrativo, si bien constituye una garantía de los derechos de los administrados, no agota con ello su función, que es, también, y muy principalmente, la de asegurar la pronta y eficaz satisfacción del interés general" ${ }^{\prime 3}$.

Es sabido que la ley austríaca de procedimiento administrativo de 1925 (la ya recordada AVG), si bien de gran relevancia dogmática, solamente logró influir en algunos ordenamientos europeos (Checoslovaquia, Polonia, Yugo-

31 García de Enterría y Fernández (2008, 453; cursiva nuestra). 
slavia), con la notoria excepción de la vecina Alemania ${ }^{32}$. Como también es conocido, ni Alemania ni otro importante vecino de Austria -Italia- tuvieron hasta bien entrado el siglo xx leyes reguladoras del procedimiento administrativo $^{33}$. Es por ello que resulta llamativo que los avances más relevantes en materia de 'sustantivación' del procedimiento provengan, precisamente, de la dogmática desarrollada en dichos ordenamientos; en el caso italiano, mucho antes de la adopción de la ley de procedimiento ${ }^{34}$.

De esta forma, como recuerda Tedeschini, en las líneas escritas por Santi Romano en la década de los veinte ya se destacaba el rol de garantía de los intereses legítimos que corresponde al procedimiento administrativo. Tal finalidad garantista se encontraba estrechamente relacionada con el principio de supremacía de la ley parlamentaria, de indiscutible raigambre liberal y, por ende, con el rol propedéutico a la dictación de un acto de ejecución de la ley que debía cumplir el procedimiento ${ }^{35}$.

Luego de la Segunda Guerra Mundial, un lucidísimo Giannini vincularía el procedimiento administrativo a la tarea de hacer notorios los intereses que se encuentren involucrados en la decisión administrativa. De este modo, para Giannini, el procedimiento administrativo es el método que el derecho entrega a la Administración para ponderar, pero, sobre todo, para llegar a conocer los intereses que se encuentran implicados en la decisión que debe adoptar.

Es significativo a este respecto que Giannini haya negado que la característica fundamental del procedimiento administrativo sea el hecho de tratarse de una secuencia de actividades ordenada a la producción de cierto tipo de acto de carácter conclusivo. El procedimiento, para Giannini, son actuaciones

32 Véase Nieto $(1960,76)$, quien explica que "la influencia de la ley austríaca de 21 de julio de 1925 sobre el procedimiento administrativo general ha sido muy grande en Centroeuropa. A su imagen y semejanza surgieron las de Checoslovaquia [...], Polonia [...] y Yugoslavia [...]. Pero Alemania no ha seguido este ejemplo, aferrándose a su tradicional minimización del procedimiento administrativo, sin tener en cuenta los elogios unánimes que prodiga la literatura al modelo austríaco". Véase, también, TEDESCHINI $(1986,873)$. En un sentido más general, en relación con la completa teoría kelseniana, Stolleis $(2004,155)$ recuerda esa fuerte influencia en los países del sudeste de Europa central: "Precisely because of these tensions, [the theory] remained initially a phenomenon that was essentially restricted to Austria and to the Austrian sphere of influence in eastern southern central Europe; even Kelsen's stay in Cologne (1930-3) did not change that".

33 Alemania aprobó solo en mayo de 1976 una ley general de procedimiento administrativo, la Verwaltungsverfahrensgesetz (VwVfG). Italia llegó a contar con una ley reguladora del procedimiento recién en 1990, año de publicación de la legge 7 agosto 1990, n. 241, titulada Nuove norme in materia di procedimento amministrativo e di diritto di accesso ai documenti amministrativi.

34 Al punto que, ya en 1986, la doctrina italiana sostenía que la idea de elaborar una ley general de procedimiento en Italia se encontraba prácticamente abandonada puesto que se había alcanzado una satisfactoria elaboración teórica y jurisprudencial de los conceptos y tipologías a través de los cuales se articula el fenómeno de la procedimentalización de las actividades administrativas. Así TeDESCHINI (1986, 873).

35 Tedeschini $(1986,874)$. 
ordenadas a la relación concreta de una pluralidad de intereses; esto es, un modo de poner en evidencia intereses que, de otra manera, se mantendrían ocultos al conocimiento y consideración de la Administración ${ }^{36}$.

Es esta función evidenciadora de intereses aquello que justifica y hace necesaria la substanciación de un procedimiento administrativo, al punto que, según Giannini, si los intereses en juego resultan ex ante evidentes, no habría necesidad de instruir procedimiento alguno para decidir. Al respecto, el autor ejemplifica su postura acudiendo a una situación en la cual la urgencia en la adopción de una decisión, así como la gravedad de la misma, no dejan lugar a dudas: el comandante de bomberos que, en una situación de emergencia, determina destruir un bien que amenaza ruina o que sufre un incendio, para evitar mayores daños a personas o cosas, sacrifica todo interés que no se condiga con dicha finalidad, precisamente, porque los intereses en juego son evidentes. Por tal razón, esta decisión viene adoptada sin observancia de procedimiento alguno ${ }^{37}$.

Por el contrario, esta función evidenciadora de los intereses, cuando ellos son efectivamente poco evidentes, explica un mayor grado de procedimentalización en la adopción de la decisión. El ejemplo que nos entrega Giannini es la contratación pública, en la cual se realiza un procedimiento previo (llamado, por nosotros, de selección del contratista y, por él, de evidenza pubblica) destinado a determinar cómo se satisface mejor el interés de la Administración contratante y, con ello, el interés público ${ }^{38}$.

Tenemos, entonces, una primera aproximación sustantiva a un fenómeno que no puede leerse únicamente a través de normas ordenadoras de la conducta administrativa y que debe ser interpretado a la luz de los fines que busca alcanzar la substanciación de todo procedimiento administrativo. Para Giannini, tal fin es evidenciar los intereses que la Administración debe ponderar para decidir, esto es, para emanar un acto administrativo terminal o, en la terminología peninsular, un provvedimento amministrativo.

36 Giannini $(2000,271)$, donde se afirma que "ciò che contraddistingue il procedimento amministrativo dagli altri procedimenti comunque denominati non è allora l'essere sequenza di atti ordinati al fine della produzione di un certo atto di carattere conclusivo, poiché questa vi è per tanti altri atti di pubblici poteri (la legge, la sentenza, la costituzione del parlamento, ecc.), ma l'essere sequenza ordinata al raccordo concreto di una pluralità di interessi"; de igual parecer, TEDESCHINI $(1986,876)$, para quien el procedimiento se encuentra ordenado "all'evidenza degli interessi". En igual sentido, más recientemente, CASETTA $(2008,384)$, asevera que el procedimiento encuentra su razón de ser en "la necessità di dare evidenza alle modalità di scelta effettuate dall'amministrazione in vista dell'interesse pubblico".

37 Giannini $(2000,272)$. El ejemplo naturalmente considera que el cuerpo de bomberos es un órgano de la Administración del Estado, como en efecto lo es el cuerpo de vigili del fuoco en Italia.

38 GianNini (2000, 272). Véase, especialmente, GianNini (2000, 502): en la contratación pública "si svolgono dei procedimenti amministrativi aventi lo scopo di rendere conoscibili (di pubblica ragione come altri dice), anche mediante controlli, i motivi di pubblico interesse specifici del contratto". 
Tan relevante es la lectura sustancialista en la doctrina italiana que la literatura más reciente llega a calificar de indebidamente aséptica y neutral la definición meramente procedimental del procedimiento administrativo. De esta suerte, sostiene la doctrina italiana, cualquier intento definitorio del instituto debe necesariamente llenar de contenido material las secuencias procedimentales y ligar el procedimiento a reglas de contenido sustancial. Por tal razón, cualquier procedimiento que no satisfaga dichos estándares deberá dejar de considerarse 'procedimiento administrativo'. De este modo, solo será considerado tal aquel conjunto de reglas caracterizadas por un estatuto disciplinar de garantía, no solo para el administrado, sino también para la misma Administración Pública. Y esto porque el procedimiento es la sede donde se comparan y equilibran los intereses generales que la Administración debe satisfacer con los intereses privados, que son 'tocados' por la decisión administrativa ${ }^{39}$.

Como puede verse, en esta opinión se advierte, nuevamente, el tópico de la protección del equilibrio entre intereses que debe informar el procedimiento administrativo. Este equilibrio de intereses -si atendemos a la definición gianniniana- se obtendrá únicamente si ellos resultan conocidos o evidentes para la Administración encargada de decidir. Esto no quiere decir otra cosa -obvia, por lo demás- que si la Administración llamada a adoptar un acto administrativo carece de conocimiento acerca de los intereses en juego, en su decisión no podrá ponderarlos y, como consecuencia, carecerá de la información necesaria para adoptar la decisión que mejor satisfaga el interés general.

Por ende, debe identificarse la recopilación de información como una de las finalidades fundamentales del procedimiento administrativo. Y este fin se encuentra recogido como elemento determinante de la comprensión que la más autorizada doctrina alemana tiene sobre el procedimiento. En efecto, Schmidt-Aßmann nos entrega una definición en la cual sostiene que los procedimientos administrativos son "secuencias organizadas de obtención y tratamiento de la información bajo la responsabilidad de un ente administrativo", agregando que el procedimiento da una "estructura a los múltiples contactos que se producen entre la Administración y los ciudadanos o entre distintas unidades administrativas" ${ }^{40}$.

Puede advertirse acá, nuevamente, que la doctrina europea pone el acento en la revelación de los intereses subyacentes o susceptibles de ser 'tocados' por la decisión administrativa y en la necesidad de que la existencia, naturaleza y contenidos de dichos intereses lleguen a estar efectivamente en conocimiento de la autoridad administrativa llamada a dictar el acto.

39 FERRARA $(2008,105-108)$.

40 Schmidt-Assmann $(2003,358)$. En Chile adoptan esta comprensión Bermúdez Soto $(2014,192)$ y CORDERO VEGA $(2015,342)$. 
Resulta relevante recordar que, para Schmidt-Aßmann, el procedimiento cobra especial importancia durante la adopción de decisiones regladas, ya que estas, no obstante tal carácter, dejan un amplio espacio para la discrecionalidad. Tal como lo sostenía Merkl, para Schmidt-Aßmann, la función del procedimiento es permitir controlar la adopción de estas decisiones en las que el margen de arbitrio administrativo se encuentra siempre presente.

Sin embargo, el autor reconoce que el procedimiento administrativo actual no se concentra de modo exclusivo en permitir el control a posteriori de la decisión administrativa sino, principalmente, en hacer posible que los interesados participen y condicionen a priori el contenido de dicha decisión. Aspectos clave del procedimiento que permiten este tipo de participación son el derecho de audiencia y el de vista del expediente ${ }^{41}$.

Como podemos apreciar, para la doctrina europea contemporánea el procedimiento administrativo se presenta como una realidad más compleja que la mera secuencia de actos que, concatenados entre sí, están destinados a la producción de una decisión terminal. Para la cultura administrativa europea el procedimiento cumple una función gravitante en la adopción de decisiones ajustadas a la ley y, sobre todo, sustantivamente legítimas. Dicha legitimidad sustantiva se alcanza gracias al adecuado flujo de información hacia el ente que debe decidir; y la información que el ente debe conocer es aquella que le permite ponderar de mejor modo los intereses que serán alcanzados por la decisión en preparación.

La pregunta que es necesario formular es, entonces, la siguiente: ¿puede llegarse a una conclusión similar en el derecho administrativo chileno?

\section{UNA COMPRENSIÓN FUNCIONAL DEL PROCEDIMIENTO ADMINISTRATIVO CHILENO}

El desafío fundamental que ha de ser asumido por la doctrina chilena es construir, a partir de las normas de la LBPA, una comprensión sustantiva o funcional del procedimiento administrativo.

Nuestra doctrina ha dado algunos pasos en esta dirección. Así, por ejemplo, Cordero Vega denuncia el rol accesorio al cual ha sido relegado el procedimiento administrativo. Dicha accesoriedad, en palabras del autor, deja de considerar la relevancia que tiene el procedimiento en la calidad de las

41 Véase Schmidt-Assmann $(2003,361)$ : "el procedimiento administrativo actual no se centra solo ni exclusivamente en posibilitar el control posterior [...] de las decisiones administrativas una vez adoptadas. Se trata más bien de condicionar a priori el modo en que se toman las decisiones administrativas [...]. Este segundo tipo de procedimiento se configura con elementos típicos del derecho de audiencia y vista del expediente y el deber de asesoramiento e información de la Administración, pero también con deberes de colaboración de los interesados”. 
decisiones administrativas, las definiciones del interés público y la eficiencia de la actividad estatal ${ }^{42}$.

El mismo autor explica que este rol accesorio del procedimiento administrativo (o, como ha sido llamado en este trabajo, 'procedimental') encuentra su explicación en el hecho de que nuestra doctrina, fiel a las tradiciones, ha puesto en el centro de su reflexión al acto administrativo, entronizándolo como producto del procedimiento el cual, por su parte, ha sido opacado como mecanismo de salvaguarda de los derechos e intereses de los administrados. La razón que explica este enfoque de análisis se encuentra en la atención que ha merecido la impugnación de la decisión terminal, lo que, inevitablemente, relega al procedimiento para su formación a un segundo plano de interés. En buenas cuentas, para nuestra doctrina tradicional el procedimiento no es otra cosa que una institución propia del acto administrativo, motivo por el cual se lo desplaza a una posición accesoria ${ }^{43}$.

Concluye el autor que "estos criterios implican ver el procedimiento administrativo en su perspectiva adjetiva meramente defensiva, con olvido de sus potencialidades en relación a la exigencia de estándares jurídicos de información de las decisiones administrativas" ${ }^{44}$.

Aparece clara la crítica que formula Cordero: nuestro procedimiento administrativo ha crecido al margen de sus verdaderas potencialidades; al margen de una comprensión que coloque al centro de su significación la importancia de la adecuada recolección de la información necesaria para la adopción de decisiones justas por parte de la Administración del Estado. El procedimiento, en definitiva, cumpliría solamente una función adjetiva o subordinada al derecho material ${ }^{45}$.

Sin embargo, en la justificación de esta crítica de Cordero a la comprensión tradicional subyace una finalidad de exacerbada protección de las posiciones jurídicas de los administrados, esto es, una pretensión fundamentalmente garantista de los derechos de los ciudadanos contra la actuación administrativa. El autor sostiene que, "en la medida que la Administración está habilitada por el ordenamiento para adoptar decisiones (pudiendo imponerlas coactivamente), susceptibles de provocar graves detrimentos en la esfera vital de los particulares afectados, es claro que resulta necesario, cuando menos,

42 Cordero Vega $(2015,318)$.

43 Cordero Vega (2015, 319-320): "Así, la influencia de la figura del acto administrativo terminal, como institución central de la formación histórica del derecho administrativo, ha provocado que el procedimiento administrativo sea mirado a través de sus lentes (perspectiva estática). El enfoque tradicional, basado en la impugnación del acto definitivo o resolución, ha provocado que el procedimiento sea considerado como un elemento formal de éste y, al ser mera forma, de escasa trascendencia".

44 Cordero Vega $(2015,321)$.

45 BARNES $(2011,84)$. Este autor, con tono crítico, continúa señalando que el procedimiento se encuentra "al servicio de la mejor aplicación del derecho. Lo relevante a la postre es que la decisión adoptada sea correcta en términos jurídicos". 
articular mecanismos que garanticen el acierto y la legalidad de la resolución finalmente adoptada" 46 .

Es claro que, si bien se reconocen en el procedimiento administrativo finalidades sustantivas, como lo es la recolección de las informaciones necesarias para el más acertado ejercicio de la competencia, dichas finalidades se explican en razón de garantizar la mayor protección del ciudadano frente al poder administrativo.

Resulta evidente que tal finalidad no es ajena ni impropia del procedimiento administrativo; sin embargo, reconocerle un carácter sustancial al procedimiento primordialmente a causa de la necesidad de proteger al ciudadano de frente a las potestades administrativas significa justificar la visión sustantiva del procedimiento a partir de la tradición que se critica, esto es, una finalidad impugnatoria del acto que afecta al ciudadano.

La lectura que se pretende ofrecer en este trabajo es que la finalidad sustantiva del procedimiento (esto es, la adquisición de informaciones que evidencien los intereses que serán alcanzados por la decisión administrativa y que permitan a la Administración ponderarlos correctamente al momento de determinar qué decisión se condice mejor con el interés público) no puede encontrar su principal explicación en la necesidad de defender las posiciones subjetivas de los particulares, sino, por el contrario, en el requerimiento de que la Administración adopte decisiones materialmente correctas y jurídicamente equilibradas para la mejor satisfacción del interés público ${ }^{47}$.

La corrección material se alcanzará solo si la Administración conoce y cuenta con todos los antecedentes necesarios para decidir. Sin embargo, esto es solo un aspecto de la justicia de la decisión. En efecto, la doctrina comparada comienza a poner en un sitial relevante el equilibrio o moderación de las medidas administrativas. Dicha moderación se alcanzará solo después de una adecuada ponderación de los intereses que se develan a partir de la información que haya logrado recolectar. Este último aspecto es denominado por la doctrina italiana como mitezza de la actividad administrativa unilateral, esto es, la ponderación y equilibrio de la decisión ejecutoria ${ }^{48}$.

En otras palabras, el procedimiento administrativo debiera ser visto como un mecanismo que permite a la Administración adquirir informaciones acerca de la existencia, el alcance, la naturaleza y las características de los múltiples intereses que confluyen en la configuración de una determinada situación para, de esta forma, poder alcanzar la decisión que mejor satisfaga el interés público y que, contemporáneamente, se ajuste al ordenamiento jurídico.

Ahora bien, cabe preguntarse: ¿es posible alcanzar una conclusión de este tipo a la luz de las disposiciones de la LBPA? Creo que sí.

46 Cordero Vega $(2015,333)$.

47 Recuérdese, nuevamente, García de Enterría y Fernández (2008, 453).

48 FERRARA $(2008,106)$. 
En efecto, si bien la LBPA se enmarca dentro de la tradición que ve el procedimiento administrativo como el camino que debe seguirse por la Administración para "hacer hablar a la ley" ${ }^{49}$, no deben pasarse por alto una serie de disposiciones que admiten ser leídas desde la óptica propuesta en este trabajo.

De esta forma, si atendemos a la finalidad informativa del procedimiento administrativo, podemos advertir que la LBPA obliga a la Administración a tomar en consideración las alegaciones y documentos que los interesados hayan podido allegar. En efecto, los artículos 10, inciso 1. ("Los interesados podrán, en cualquier momento del procedimiento, aducir alegaciones y aportar documentos u otros elementos de juicio") y 17 LBPA ("Las personas, en sus relaciones con la Administración, tienen derecho a: [...] f) formular alegaciones y aportar documentos...") atribuyen a los particulares la facultad de contribuir a la mejor información en manos de la Administración, la cual, por su parte, se encuentra obligada a tener en cuenta dichos antecedentes al momento de resolver, en conformidad con el mismo artículo 17 LBPA.

Por otro lado, si los interesados están facultados para realizar actividades destinadas a la mejor información de la Administración, esta última, al momento de decidir, junto con tener en cuenta los antecedentes eventualmente aportados por los interesados, debe expresar "los hechos y fundamentos de derecho" de su decisión, especialmente, si sus resoluciones pueden afectar los derechos de los particulares (art. 11, inc. $2 .^{\circ}$, LBPA). En virtud de este deber de motivación, la Administración se encuentra obligada a hacer explícitos los razonamientos y las consideraciones que tuvo en cuenta para adoptar su decisión. De esta manera, y en otros términos, la ley obliga a la Administración a poner de manifiesto qué tipo de información valoró al momento de resolver y, a través de este deber de motivación, poner en conocimiento de los interesados y de la comunidad en general los intereses que adquirieron primacía al momento de dictación del acto.

Sobre este último aspecto debe recordarse que el artículo 16, inciso $2 .^{\circ}$, LBPA (en relación con el artículo 8. ${ }^{\circ}$ de la Constitución Política) establece que los actos y resoluciones de los órganos de la Administración, así como sus fundamentos, tienen carácter público. Este régimen de publicidad a que se encuentran sometidos estos actos estatales permite valorar la ponderación y selección de intereses que haya hecho la Administración al momento de adoptar el acto administrativo.

Ahora bien, en materia de instrumentos procedimentales destinados a garantizar esta finalidad informativa que la doctrina contemporánea atribuye al procedimiento administrativo, la LBPA establece al menos, dos: el ante-procedimiento de 'informaciones previas' y el trámite de instrucción 
denominado 'información pública'. El primero tiene por finalidad que el órgano competente pueda "conocer las circunstancias del caso concreto y la conveniencia o no de iniciar el procedimiento" 50 . El segundo, por su parte, se encuentra encaminado a permitir que "la comunidad en general formule las observaciones que estime pertinentes relativas al procedimiento" 51 , esto es, a que "todos aquellos sujetos individuales o colectivos que puedan verse afectados por la resolución" participen del procedimiento ${ }^{52}$. La común finalidad de estas actuaciones no es otra que poner a la Administración en condiciones de recabar informaciones que puedan encontrarse a disposición de sujetos no directamente involucrados en el procedimiento respectivo y que, no obstante, sean de relevancia para resolver con conocimiento acabado de "las circunstancias del caso concreto" (art. 29, inc. 2. ${ }^{\circ}$, LBPA).

Como bien puede advertirse de esta rápida reseña de los mecanismos procedimentales puestos a disposición del órgano de instrucción del procedimiento, la LBPA -si bien no de modo sistemático- consagró disposiciones que permiten entender el procedimiento administrativo como el constructo al cual la Administración Pública puede echar mano para alcanzar un conocimiento acabado de las circunstancias de hecho y de los intereses que se encuentran involucrados en ellas y que, por tanto, pueden verse alcanzados por una determinada decisión, de modo tal que, con esta mejor y más acabada información, pueda adoptar actos administrativos que se encuentren ajustados a la legalidad sin desatender la finalidad de satisfacción del interés general de la comunidad, propia de la organización administrativa.

$\mathrm{Si}$ el procedimiento administrativo es comprendido de esta manera se podrán asignar al mismo funciones más ambiciosas y sofisticadas, que se encuentren en línea con las responsabilidades que le competen a la Administración contemporánea, entre las cuales se deben contar la configuración o dirección política de la realidad social ante la incapacidad de la ley de programar soluciones justas y adecuadas para cada caso concreto ${ }^{53}$.

\section{CONCLUSIONES}

En el presente trabajo se ha podido demostrar el amplio alcance que tiene la comprensión adjetiva o 'procedimental' del procedimiento administrativo; comprensión que se encuentra perfectamente reflejada por el artículo 18 LBPA y que, prima facie, podría sostenerse que prima en el ordenamiento jurídico chileno.

53 BaRNes $(2011,80)$. 
Los orígenes de dicho entendimiento pueden encontrarse en los primeros intentos de instauración de procedimientos formalizados (o, mejor dicho, 'juridificados') de decisión administrativa. Entre tales primeras experiencias cabe destacar la señera actividad dogmática llevada a cabo, en el seno de la Escuela de Viena, por Adolf Merkl, la cual marcó de manera indeleble la tradición administrativista continental en el sentido de entender que el procedimiento administrativo no es más que el camino que debe recorrer la Administración para aplicar la ley al caso concreto, esto es, el sustrato formal de toda decisión de aplicación del derecho formulada por el órgano administrativo.

Por otro lado, la dogmática administrativa de países europeos que no fueron alcanzados por la tendencia 'procedimentalizadora' de la doctrina vienesa ha sido aquella que ha producido comprensiones sustantivas del procedimiento administrativo. Dichas doctrinas advierten que el procedimiento administrativo es un mecanismo que permite a la Administración develar los intereses que debe ponderar al momento de adoptar un provvedimento administrativo (Giannini) y que, por ello, este procedimiento no es otra cosa que una herramienta que permite nutrir a la Administración de las informaciones imprescindibles para adoptar actos administrativos que satisfagan de la mejor manera los intereses públicos (Schmidt-Aßmann).

Esta lectura del procedimiento administrativo no es extraña a aquella que puede realizarse en Chile a partir de determinadas disposiciones de la LBPA, conforme a las cuales no queda duda de que subyace a su regulación la intención de dotar a la Administración Pública de los instrumentos necesarios para adquirir y tratar la información requerida para adoptar decisiones que le permitan cumplir con su finalidad de promover el bien común atendiendo las necesidades públicas en forma continua y permanente.

\section{REFERENCIAS}

BARnes, J. (2011). Tres generaciones del procedimiento administrativo. Revista de la Facultad de Derecho de la Pontificia Universidad Católica del Perú. Vol. 67.

Bermúdez Soto, J. (2014). Derecho administrativo general.3. a ed. Santiago: Legal-Publishing.

Bocksang Hola, G. (2006). El procedimiento administrativo chileno. Santiago: LexisNexis.

Brewer-Carías, A. R. (1990). Principios del procedimiento administrativo. Madrid: Civitas.

Carrino, A. (2016). Logistic Normativism: The Wiener rechtstheoretische Schule. En Pattaro, E. y Roversi, C., eds. Legal Philosophy in the Twentieth Century: The Civil Law World. Netherlands: Springer.

Casetta, E. (2008). Manuale di diritto amministrativo. 10. ${ }^{\text {a }}$ ed. Milano: Giuffrè.

Cordero Vega, L. (2003). El procedimiento administrativo. Santiago: LexisNexis. 
Cordero Vega, L. (2015). Lecciones de derecho administrativo. Santiago: Legal-Publishing.

Cordero Vega, L. (2016). De Marín a Pierry: 20 años en el desarrollo de la responsabilidad del Estado en la Corte Suprema. En Ferrada Bórquez, J. C.; Bermúdez Soto, J. y Urrutia Silva, O., eds. Doctrina y enseñanza del derecho administrativo chileno: Estudios en homenaje a Pedro Pierry. Valparaíso: Ediciones Universitarias de Valparaíso.

Ferrara, R. (2008). Introduzione al diritto amministrativo. 2. ${ }^{\text {a }}$ ed. Roma-Bari: Laterza.

García de Enterría, E. y Fernández, T.-R. (2008). Curso de derecho administrativo. T. II. 11. ${ }^{\text {a }}$ ed. Madrid: Thomson Civitas.

Giannini, M. S. (2000). Istituzioni di diritto amministrativo. 2. a ed. Milano: Giuffrè.

Jara Schnettler, J. (2013). La Contraloría General de la República y su contribución al surgimiento y evolución del procedimiento administrativo en Chile. Revista de Derecho Público. Vol. 78.

Kelsen, H. (2011). Teoría pura del derecho. Introducción a los problemas de la ciencia jurídica. Trad. $1^{\text {a }}$ ed. Reine Rechtslehre (1934). Madrid: Trotta.

López-Nieto y Mallo, F. (1960). El procedimiento administrativo. Barcelona: Bosch.

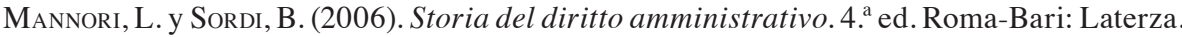

Merkl, A. (2004). Teoría general del derecho administrativo. Granada: Comares.

Nieto, A. (1960). El procedimiento administrativo en la doctrina y legislación alemanas. Revista de Administración Pública. Vol. 32.

Parejo Alfonso, L. (2012). Lecciones de derecho administrativo. 5. a ed. Valencia: Tirant lo Blanch

Paulson, S. L. (2013). How Merkl's Stufenbaulehre informs Kelsen's concept of law. Revus. Vol. 21.

Rojas Varas, J. (2004). Notas sobre el procedimiento administrativo establecido en la Ley n. ${ }^{\circ}$ 19.880. Revista de Derecho del Consejo de Defensa del Estado. Vol. 11.

Schmidt-AssMann, E. (2003). La teoría general del derecho administrativo como sistema. Objeto y fundamentos de la construcción sistemática. Madrid-Barcelona: Marcial Pons.

SORDI, B. (1987). Tra Weimar e Vienna. Amministrazione pubblica e teoria giuridica nel primo dopoguerra. Milano: Giuffrè.

Stolleis, M. (2004). A history of public law in Germany, 1914-1945. Oxford: Oxford University Press.

Tedeschini, F. (1986). Procedimento amministrativo (ad vocem). Enciclopedia del diritto. Milano: Giuffrè. 